Fixed Point Theory, 22(2021), No. 2, 527-542

DOI: $10.24193 /$ fpt-ro.2021.2.35

http://www.math.ubbcluj.ro/ nodeacj/sfptcj.html

\title{
BOUNDARY VALUE PROBLEM FOR DIFFERENTIAL EQUATIONS WITH GENERALIZED HILFER-TYPE FRACTIONAL DERIVATIVE
}

\author{
MOUFFAK BENCHOHRA*,**, SOUFYANE BOURIAH*** AND JUAN J. NIETO**** \\ * Laboratory of Mathematics, Djillali Liabes University of Sidi Bel-Abbes, \\ P.O. Box 89 Sidi Bel Abbes 22000, Algeria \\ E-mail:benchohra@yahoo.com \\ ${ }^{* *}$ Department of Mathematics, College of Science, King Saud University, \\ P.O. Box 2455, Riyadh 11451, Saudi Arabia \\ *** Department of Mathematics, Faculty of Exact Sciences and Informatics, \\ Hassiba Benbouali University, P.O. Box 151 Chlef 02000, Algeria \\ E-mail:s.bouriah@univ-chlef.dz; bouriahsoufiane@yahoo.fr \\ **** Departamento de Estatistica, Análise Matemática e Optimización, Instituto de Matemáticas, \\ Universidade de Santiago de Compostela, Santiago de Compostela, Spain \\ E-mail: juanjose.nieto.roig@usc.es
}

\begin{abstract}
In this paper, we establish the existence and uniqueness of solutions to boundary value problem for differential equations with generalized Hilfer type fractional derivative. The arguments are based upon the Banach contraction principle and Krasnoselskii's fixed point theorem. An example is included to show the applicability of our results.
\end{abstract}

Key Words and Phrases: Generalized Hilfer type fractional derivative, boundary value problem, existence, uniqueness, fixed point.

2020 Mathematics Subject Classification: 26A33, 34A08, 34B15, 47H10.

Acknowledgement. The authors are grateful to the referee for the helpful remarks. The research of J.J. Nieto has been partially supported by the AEI of Spain under Grant MTM2016-75140-P and co-financed by European Community fund FEDER. This paper was completed while the second author was visiting the university of Santiago de Compostela. He is grateful for the warm hospitality.

\section{REFERENCES}

[1] S. Abbas, M. Benchohra, S. Bouriah, J.J. Nieto, Periodic solutions for nonlinear fractional differential systems, Differ. Equ. Appl., 10(2018), 299-316.

[2] S. Abbas, M. Benchohra, J.R. Graef, J. Henderson, Implicit Differential and Integral Equations: Existence and stability, Walter de Gruyter, London, 2018.

[3] S. Abbas, M. Benchohra, G.M. N'Guérékata, Topics in Fractional Differential Equations, Springer-Verlag, New York, 2012. 
[4] S. Abbas, M. Benchohra, G.M. N'Guérékata, Advanced Fractional Differential and Integral Equations, Nova Science Publishers, New York, 2014.

[5] B. Ahmad, A. Alsaedi, S.K. Ntouyas, J. Tariboon, Hadamard-type Fractional Differential Equations, Inclusions and Inequalities, Springer, Cham, 2017.

[6] B. Ahmad, S.K. Ntouyas, Fractional differential inclusions with fractional separated boundary conditions, Fract. Calc. Appl. Anal., 15(2012), 362-382.

[7] R. Almeida, A.B. Malinowska, T. Odzijewicz, Fractional differential equations with dependence on the Caputo-Katugampola derivative, J. Comput. Nonlinear Dynam., 11(6)(2016), 1-11.

[8] B. Al-Saqabi, V.S. Kiryakova, Explicit solutions of fractional integral and differential equations involving Erdélyi-Kober operators, Appl. Math. Comput., 95(1998), no. 1, 1-13.

[9] D. Baleanu, Z.B. Güvenç, J.A.T. Machado, New Trends in Nanotechnology and Fractional Calculus Applications, Springer, New York, 2010.

[10] D. Baleanu, S.D. Purohit, J.C. Prajapati, Integral inequalities involving generalized ErdélyiKober fractional integral operators, Open Math., 14(2016), 89-99.

[11] M. Benchohra, S. Bouriah, M.A. Darwish, Nonlinear boundary value problem for implicit differential equations of fractional order in Banach spaces, Fixed Point Theory, 18(2017), no. 2, 457-470.

[12] M. Benchohra, S. Bouriah, J.R. Graef, Boundary value problems for nonlinear implicit CaputoHadamard-type fractional differential equations with impulses, Mediterr. J. Math., (2017), 14:206.

[13] M. Benchohra, S. Bouriah, J.R. Graef, Nonlinear implicit differential equations of fractional order at resonance, Electron. J. Differential Equations, 2016(2016), no. 324, 1-10.

[14] F.Z. Berrabah, B. Hedia, J. Henderson, A fully Hadamard and Erdélyi-Kober-type integral boundary value problem of a coupled system of implicit differential equations, Turkish J. Math., 43(2019), no. 3, 1308-1329.

[15] A. Erdélyi, H. Kober, Some remarks on Hankel transforms, Quart. J. Math., Oxford, Second Ser., 11(1940), 212-221.

[16] Y.Y. Gambo, F. Jarad, D. Baleanu, T. Abdeljawad, On Caputo modification of the Hadamard fractional derivatives, Adv. Difference Equa., 2014(2014), no. 1, 1-12.

[17] A. Granas, J. Dugundji, Fixed Point Theory, Springer-Verlag, New York, 2003.

[18] R. Hilfer, Applications of Fractional Calculus in Physics, World Scientific, Singapore, 2000.

[19] R. Hilfer, Threefold Introduction to Fractional Derivatives, In: Anomalous Transport, pages 17-73, Wiley-VCH Verlag GmbH et Co.KGaA, 2008.

[20] M.D. Kassim, N.E. Tatar, Well-posedness and stability for a differential problem with HilferHadamard fractional derivative, Abst. Appl. Anal, 2014(2014), 1-7.

[21] A.A. Kilbas, H.M. Srivastava, J.J. Trujillo, Theory and Applications of Fractional Differential Equations, North-Holland Mathematics Studies, 204, Elsevier Science B.V., Amsterdam, 2006.

[22] V. Kiryakova, Generalized Fractional Calculus and Applications, Pitman Res. Notes Math. Ser. 301, Longman Scientific \& Technical, Harlow, 1994.

[23] V. Kiryakova, Y. Luchko, Multiple Erdélyi-Kober integrals and derivatives as operators of generalized fractional calculus, Handbook of Fractional Calculus with Applications, Vol. 1, 127-158, De Gruyter, Berlin, 2019.

[24] Y. Luchko, J.J. Trujillo, Caputo-type modification of the Erdélyi-Kober fractional derivative, Fract. Calc. Appl. Anal., 10(2007), no. 3, 249-267.

[25] A.M. Mathai, H.J. Haubold, Erdélyi-Kober Fractional Calculus. From a Statistical Perspective, Inspired by Solar Neutrino Physics, Springer Briefs in Mathematical Physics, 31, Springer, Singapore, 2018.

[26] D.S. Oliveira, E. Capelas de Oliveira, Hilfer-Katugampola Fractional derivatives, Comput. Appl. Math., 37(2018), no. 3, 3672-3690.

[27] W. Wei, X. Xiang, Y. Peng, Nonlinear impulsive integro-differential equations of mixed type and optimal controls, Optimization, 55(2006), 141-156.

Received: April 18, 2019; Accepted: February 12, 2020. 